\title{
Спутниковый мониторинг и сейсмическая активность Балтийского щита
}

\author{
Гусева Т.В., Крупенникова И.С., Мокрова А.Н., Розенберг Н.К. \\ Институт физики Земли им. О.Ю. Шмидта РАН (ИФ3 РАН), Москва, guseva@ifz.ru, ik@ifz.ru, \\ rosenna@ifz.ru,annmok@ifz.ru
}

Аннотация. Анализируются результаты, полученные по наблюдениям ГНСС (глобальные навигационные спутниковые системы GPS/ГЛОНАCC) в ходе изучения современной внутриплитовой геодинамики Балтийского щита за период 2006-2018 гг. Данные повторных ГНСС измерений подтвердили, что сводообразное поднятие, приуроченное к Балтийскому щиту, продолжается со скоростью до 10.4 мм/год. В пределах российской части скорость поднятия достигает 6 мм/год. Горизонтальные смещения пунктов ГНСС, вычисленные в координатной системе ITRF, имеют северо-восточное направление и среднюю скорость (по аппроксимированным данным за 2006-2018 гг.) от 19.9 мм/год на севере до 23.9 мм/год на юге. Деформационное поле региона неравномерно, протяженные зоны сжатия и растяжения сменяют друг друга, со значениями от $(-8) \times 10^{-9}$ до $16 \times 10^{-9}$. По данным каталога землетрясений за период 2000-2018 гг. рассчитана суммарная сейсмическая энергия $\left(E_{s}\right)$, выделившаяся в результате местных тектонических землетрясений. Распределение сейсмической энергии в пределах рассматриваемой области достаточно неоднородно. На западе наблюдается область меридиональной направленности, характеризующаяся сейсмической активностью $E_{s}$, достигающей $10^{11}$ Дж/10 000км², приуроченная к зоне растяжения с деформациями до $8 \times 10^{-9}$ в год. В Ладожско-Онежском районе зона сейсмической активности с $E_{s}$ порядка $10^{7}$ Дж/10 000км² вытянута с юго-запада на северо-восток и приурочена к переходному участку сжатия и растяжения. Сопоставление скоростей перемещений, деформаций и сейсмичности определяет количественные характеристики современной геодинамики исследуемого региона.

Ключевые слова: ГНСС, спутниковые измерения, сейсмичность, движения, деформации, мониторинг, Балтийский щит.

\section{Satellite monitoring and seismic activity of the Baltic Shield}

\author{
Guseva T.V., Krupennikova I.S., Mokrova A.N., Rozenberg N.K. \\ Schmidt Institute of Physics of the EarthRAS, Moscow,guseva@ifz.ru, ik@ifz.ru, rosenna@ifz.ru, \\ annmok@ifz.ru
}

\begin{abstract}
Data obtained from GNSS observations (global navigation satellite system GPS/GLONASS) in the study of the modern intraplate geodynamics of the Baltic Shield in 2006-2018 are analyzed. Repeated GNSS measurements confirmed that dome-shaped lifting, confined to the Baltic Shield, continues with a velocity $10.4 \mathrm{~mm} /$ year. In the Russian territory the rate of uplifting reaches $6 \mathrm{~mm} /$ year. Horizontal displacements of GNSS stations in the ITRF have the north-eastem direction and average velocities (according to approximated data for 2006-2018) from $19.9 \mathrm{~mm} /$ year in the north to $23.9 \mathrm{~mm} /$ year in the south. The deformation field of the region is non-homogeneous, the extended compression and extension zones follow each other, with values from $(-8) \times 10^{-9}$ to $16 \times 10^{-9}$. According to the earthquake catalogue for 2000-2018, the total seismic energy $\left(E_{s}\right)$ released in result of local tectonic earthquakes was calculated. The distribution of seismic energy within the considered area is rather heterogeneous. In the western part, there is a region of meridional orientation, characterized by seismic activity with $E_{s}$ to $10^{11} \mathrm{~J} / 10000 \mathrm{~km}^{2}$, confined to the extension zone with deformations up to $8 \times 10^{-9}$ per year. In the Ladoga-Onega region, the seismic activity zone with $E_{s}$ about $10^{7} \mathrm{~J} / 10000 \mathrm{~km}^{2}$ is extended from the south-west to the north-east and is confined to the transition area of compression and extension. The comparison of the displacements velocities, deformations and seismicity determines the quantitative characteristics of the modern geodynamics of the studied region.
\end{abstract}

Key words: GNSS, satellite measurements, seismicity, movements, deformations, monitoring, Baltic shield.

\section{введение}

Представленное исследование является продолжением работ по изучению современной геодинамики северо-запада России и прилегающих территорий на основе данных, полученных с помощью ГНСС технологий (глобальных навигационных спутниковых систем GPS/ГЛОНАCC), нача- 
тых сотрудниками ИФЗ РАН в рамках международного сотрудничества с зарубежными специалистами (Прилепин и др., 2002; Галаганов и др., 2016).

Исследуемая территория включает Балтийский щит, являющийся выступом докембрийского фундамента Восточно-Европейской платформы (ВЕП), и характеризуется слабой сейсмической активностью. Предполагается (Юдахин и др., 2003), что возникновение тектонической сейсмичности наблюдается на тех участках земной коры, которые испытывают интенсивное горизонтальное сжатие, достаточное для перехода массива в предельно-напряженное состояние. Изучение и анализ современных движений, деформаций и сейсмичности необходимы в исследуемом регионе в целях повышения безопасности строительства и эксплуатации ответственных инженерных объектов, в том числе действующих и строящихся АЭС (Кольская, Ленинградская).

При исследовании современных движений и деформаций земной коры были использованы данные повторных спутниковых измерений ГНСС, выполненных сотрудниками ИФЗ РАН на пунктах, расположенных в Карелии (наблюдения в период 2006-2018 гг.) и Ленинградской области (наблюдения в 2007-2018 гг.), а также измерений на 20 постоянно действующих станциях Международной геодинамической сети (IGS) в России, Финляндии, Швеции и Норвегии.

Повторные GPS/ГЛОНАСС наблюдения проводились ежегодно или через год в июле-августе сеансами по 3-13 суток с помощью двухчастотных приемников Javad Maxor. В результате выполнения повторных измерений и обработки по программе Bernese были определены среднесуточные и средние на эпоху наблюдений геоцентрические и геодезические координаты пунктов в ITRF. B качестве опорных были приняты ближайшие пункты IGS.

Определены также скорости горизонтальных и вертикальных движений за разные временные интервалы. Кроме того, были рассчитаны скорости площадных деформаций и проведено их сопоставление с распределением выделившейся сейсмической энергии.

\section{Движения и деформации}

Горизонтальные перемещения пунктов GPS на исследуемой части Евразии по результатам линейной аппроксимации за период 2006-2018 гг. имеют северо-восточное направление и происходят со средней скоростью от 19.9 мм/год на севере региона до 23.9 мм/год на юге. Вертикальные движения отражают сводовое поднятие со скоростью до 10.4 мм/год (рис.1), на российской территории не превышая 5-6 мм/год.

Значения скоростей горизонтальных движений по модели ITRF в значительной мере отражают движение Евразийской тектонической плиты. Чтобы оценить значения горизонтальных движений внутри исследуемого региона, выполнен расчет смещений относительно пункта KIRU, находящегося на северо-западе исследуемой территории. Горизонтальные скорости имеют значения от 0.8 мм/год на северо-западе до 5.8 мм/год на юго-востоке (рис. 2), а их направление - преимущественно юго-восточное.

Для получения площадных деформаций был рассчитан первый инвариант тензора деформаций (рис. 2). Деформационное поле региона неравномерно, протяженные зоны сжатия и растяжения сменяют друг друга, достигая значений $(-8 \div 16) \times 10^{-9}$ в год.

\section{Сейсмичность}

За период 2000-2018 гг. на рассматриваемой территории по данным КоФ ФИЦ ЕГС РАН было зафиксированно 147 сейсмических событий с магнитудами (Ml) от 0.3 до 4.1. Расчет сейсмической энергии, выделившейся в результате землетрясений, проводился с помощью разработанного авторами программного обеспечения.Территория была разбита ячейками по 10000 км², для каждой из которых проведено суммирование сейсмической энергии всех землетрясений за 2000-2018 гг.

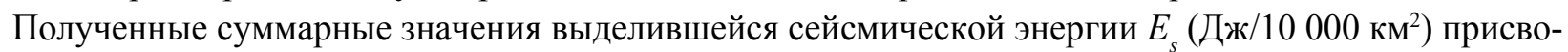
ены центру каждой ячейки (рис. 3).

Распределение сейсмической энергии в пределах рассматриваемой области достаточно неоднородно. На западе наблюдается упорядоченная цепочка элементов сейсмической активности меридиональной направленности со значениями $E_{s}$ до $10^{11}$, приуроченная к зоне растяжения, зна- 


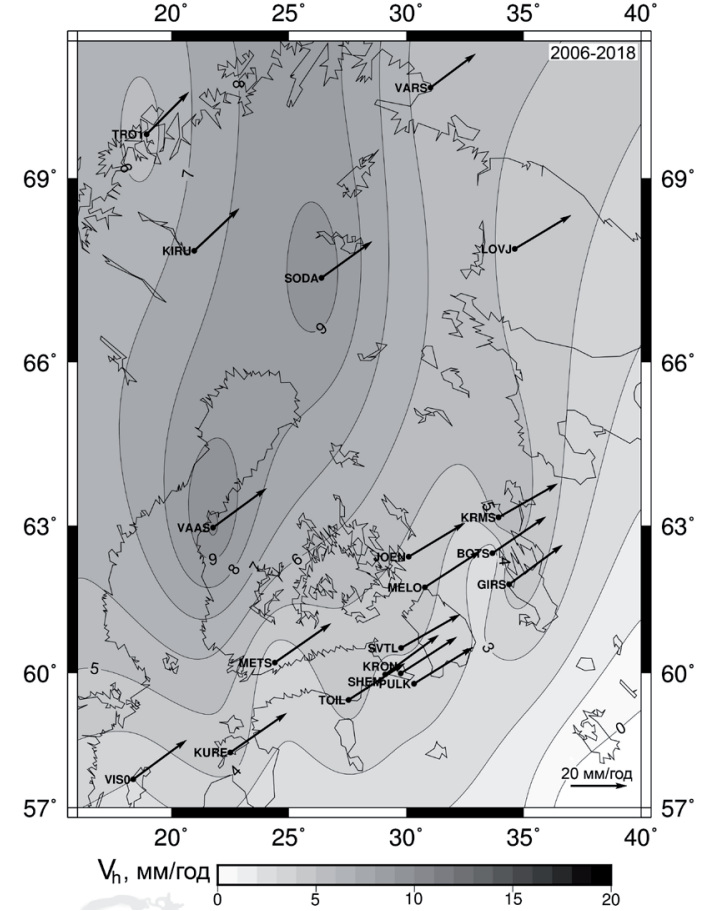

Рис. 1. Карта скоростей вертикальных движений (изолинии) и векторов скоростей горизонтальных движений (стрелки) за период 2006-2018 гг. в ITRF.

Fig. 1. Map of velocities of vertical movements (contours) and velocity of horizontal movements vectors (arrows) in 2006-2018 in ITRF.

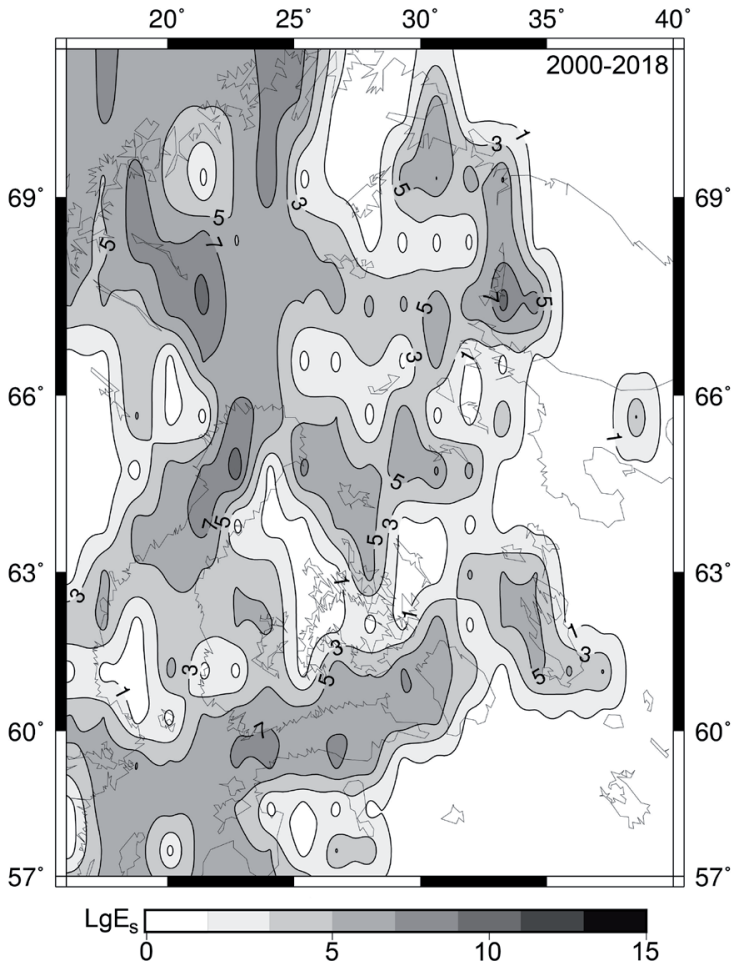

Рис. 3 Распределение логарифма суммарной сейсмической энергии Es за период 2000 -2018 гг.

Fig. 3. Distribution of the logarithm of the total seismic energy Es in 2000-2018.

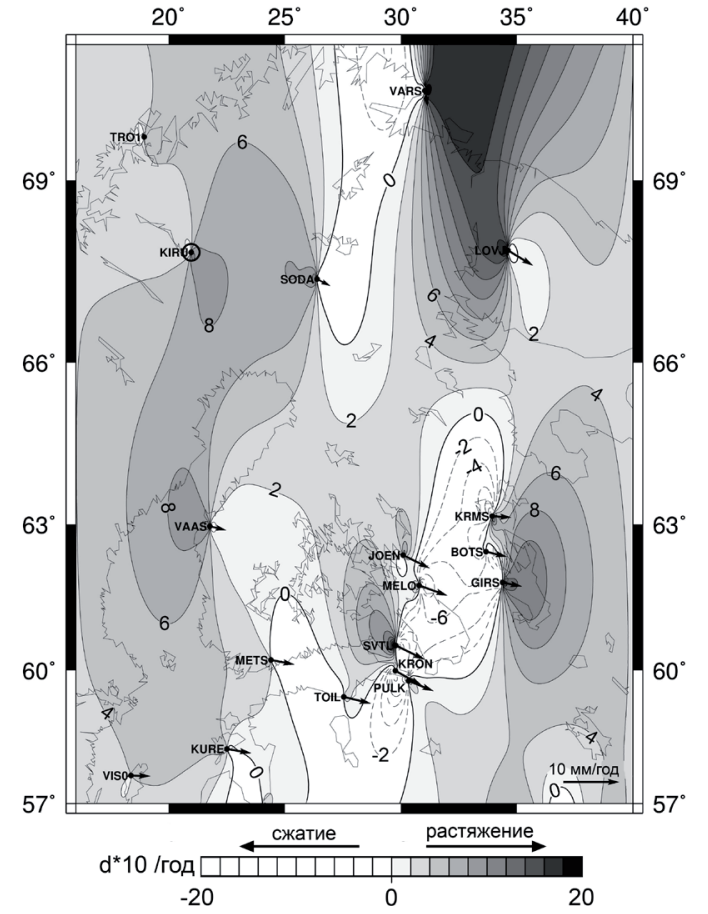

Рис. 2. Карты скоростей площадных деформаций и векторов скоростей горизонтальных смещений относительно закрепленного пункта KIRU за 2006-2018 гг.

Fig. 2. Maps of velocities of areal deformations and vectors of horizontal displacements velocities relative to the fixed station KIRU in 2006-2018.

чения которого достигают $8 \times 10^{-9}$ в год. Обращает на себя внимание область, вытянутая в пространстве с юго-запада на северо-восток, где суммарная сейсмическая энергия $E_{s}$ достигает значений $10^{7}$. Эта область характеризуется переходом от деформаций сжатия к деформациям растяжения.

\section{Заключение}

Результаты выполненных исследований с использованием ГНСС технологий и анализа сейсмичности позволяют оценить современную тектоническую активность Фенноскандии:

- продолжается сводообразное поднятие Балтийского щита со скоростью до 10.4 мм/год, которое в пределах российской территории достигает 6 мм/год;

- горизонтальные смещения пунктов ГНСС, имеющие северо-восточное направление и среднюю скорость от 19.9 мм/год на севере до 23.9 мм/ год на юге, отражают характер движения Евразии по модели ITRF; местные внутриплитовые горизонтальные перемещения достигают 5.8 мм/год на юго-востоке относительно нулевых значений на севере; 
- использованная методика анализа деформирования земной коры выявила наличие чередующихся зон растяжения и сжатия со значениями деформаций $(-8 \div 16) \times 10^{-9}$ в год.

-проявление сейсмичности в пределах рассматриваемой территории достаточно неоднородно, выделяются области, приуроченные к зонам, переходным от растяжения к сжатию, или к зонам растяжения;

- сопоставление скоростей перемещений, деформаций и сейсмичности определяет количественные характеристики современной геодинамики исследуемого региона.

\section{Литература}

1. Галаганов О.Н., Гусева Т.В., Крупенникова И.С., Мокрова А.Н., Передерин В.П. Деформационный мониторинг как индикатор техногенного влияния на геолого-экологическую среду // Мониторинг. Наука и технологии. 2016. № 2 (27). С. 40-473.

2. Прилепин М.T., Мишин А.В., Кабан М.К., Баранова С.M. GPS изучение геодинамики Балтийского щита // Физика Земли. 2002. № 9. С. 49-58.

3. Юдахин Ф.Н., Щукин Ю.К. Макаров В.И. Глубинное строение и современные геодинамические процессы в литосфере Восточно-Европейской платформы. Екатеринбург: УрО РАН. 2003. 299 с. 